\title{
Fatty Acid Binding Protein 4 (FABP4) Overexpression in Intratumoral Hepatic Stellate Cells within Hepatocellular Carcinoma with Metabolic Risk Factors
}

\author{
Norimichi Chiyonobu, ${ }^{* \dagger}$ Shu Shimada, ${ }^{*}$ Yoshimitsu Akiyama, ${ }^{*}$ Kaoru Mogushi, ${ }^{*}$ Michiko Itoh ${ }^{\ddagger}$ Keiichi Akahoshi, ${ }^{\dagger}$ \\ Satoshi Matsumura, ${ }^{\dagger}$ Kosuke Ogawa, ${ }^{\dagger}$ Hiroaki Ono, ${ }^{\dagger}$ Yusuke Mitsunori, $^{\dagger}$ Daisuke Ban, ${ }^{\dagger}$ Atsushi Kudo, ${ }^{\dagger}$ Shigeki Arii, \\ Takayoshi Suganami, ${ }^{\S}$ Shoji Yamaoka, ${ }^{\oplus}$ Yoshihiro Ogawa, ${ }^{\| * * \dagger}{ }^{\dagger}$ Minoru Tanabe, ${ }^{\dagger}$ and Shinji Tanaka* ${ }^{* \dagger}$
}

\begin{abstract}
From the Departments of Molecular Oncology, ${ }^{*}$ Hepato-Biliary-Pancreatic Surgery, ${ }^{\dagger}$ Organ Network and Metabolism, ${ }^{\ddagger}$ Molecular Virology, ${ }^{\top}$ and Molecular and Cellular Metabolism,** Graduate School of Medicine, Tokyo Medical and Dental University, Tokyo; the Department of Molecular Medicine and Metabolism, ${ }^{\S}$ Research Institute of Environmental Medicine, Nagoya University, Nagoya; the Department of Medical and Bioregulatory Science, ${ }^{\|}$Graduate School of Medical Sciences, Kyushu University, Fukuoka; and the Japan Agency for Medical Research and Development-Core Research for Evolutional Science and Technology (AMED-CREST), ${ }^{\dagger \dagger}$ Tokyo, Japan
\end{abstract}

\author{
Accepted for publication \\ January 16,2018 \\ Address correspondence to \\ Shinji Tanaka, M.D., Ph.D., \\ F.A.C.S., Department of \\ Molecular Oncology, Graduate \\ School of Medicine, Tokyo \\ Medical and Dental University, \\ 1-5-45 Yushima, Bunkyo-ku, \\ Tokyo 113-8519, Japan. E-mail: \\ tanaka.monc@tmd.ac.jp.
}

\begin{abstract}
Metabolic syndrome is a newly identified risk factor for hepatocellular carcinoma (HCC); however, tumorspecific biomarkers still remain unclear. We performed cross-species analysis to compare gene signatures of HCC from human patients and melanocortin 4 receptor-knockout mice, which develop HCC with obesity, insulin resistance, and dyslipidemia. Unsupervised hierarchical clustering and principle component analysis of 746 differentially expressed orthologous genes classified HCC of 152 human patients and melanocortin 4 receptor-knockout mice into two distinct subgroups, one of which included mouse HCC and was causatively associated with metabolic risk factors. Nine genes commonly overexpressed in human and mouse metabolic disease-associated HCC were identified; fatty acid binding protein 4 (FABP4) was remarkably enriched in intratumoral activated hepatic stellate cells (HSCs). Subclones constitutively expressing FABP4 were established from a human HSC cell line in which expression levels of inflammatory chemokines, including IL$1 \mathrm{~A}$ and IL-6, were up-regulated through NF- $\mathrm{B}$ nuclear translocation, resulting in recruitment of macrophages. An immunohistochemical validation study of 106 additional human HCC samples indicated that FABP4-positive HSCs were distributed in tumors of 38 cases, and the FABP4-high group consisted of patients with nonviral and nonalcoholic HCC $(P=0.027)$ and with multiple metabolic risk factors $(P<0.001)$ compared with the FABP4-low group. Thus, FABP4 overexpression in HSCs may contribute to hepatocarcinogenesis in patients with metabolic risk factors by modulation of inflammatory pathways. (Am J Pathol 2018, 188: 1213-1224; https://doi.org/10.1016/j.ajpath.2018.01.012)
\end{abstract}

Liver cancer is the fifth (men) and ninth (women) most common cancer, but it ranks as the second leading cause of cancerrelated deaths in the world. ${ }^{1}$ Hepatocellular carcinoma (HCC) is the most frequent histologic type of liver cancer and develops because of various causative factors, such as chronic infection with hepatitis $B$ virus (HBV) and hepatitis $\mathrm{C}$ virus (HCV) and alcohol consumption. ${ }^{2,3}$ Metabolic syndrome, a complex constellation of disorders that include obesity, hyperglycemia, and dyslipidemia, has received increasing attention as a novel risk factor for HCC in recent years. ${ }^{4,5}$ In a

\footnotetext{
Supported by a Grant-in-Aid for Scientific Research (A) from the Ministry of Education, Culture, Sports, Science and Technology of Japan; a research grant from the Princess Takamatsu Cancer Research Fund (S.T.); and P-CREATE grant JP17cm0106518 and Program for Basic and Clinical Research on Hepatitis grant JP17fk0210304 from the Japan Agency for Medical Research and Development (S.T.).

Disclosures: M.I. is assigned to Joint Research Department of Tokyo Medical and Dental University and Shionogi \& Co. Ltd.
} 
large prospective cohort study in the United States, the relative risk of liver cancer death increased with body mass index, reaching 4.52 in men with excess weight matched with men with normal weight. ${ }^{6}$ A systematic review of 13 case-control and 13 cohort studies concludes that diabetes is associated with an increased risk of HCC (pooled odds ratio, 2.54; pooled risk ratio, 2.50), independently of viral infection or alcohol abuse. ${ }^{7}$ Although these epidemiologic studies discovered the positive relationship between metabolic syndrome and HCC, the tumor characteristics still remain elusive.

Animal models are extensively used for examining the molecular events under the conditions that mimic human disease. Several mouse models for HCC associated with metabolic disease have been established by using specific diets, chemotoxic agents, genetic engineering, or combinations thereof. Mice fed methionine- and choline-deficient diets are conventional models of nonalcoholic steatohepatitis, but they undergo weight loss. ${ }^{9}$ Although high-fat diets (HFDs) promote hepatic lipid accumulation, long-term exposure is required for tumor development. ${ }^{10}$ Streptozotocin, a compound selectively eliminating $\beta$ cells in the pancreas and resulting in type 1 diabetes, in combination with HFDs induces nonalcoholic steatohepatitis and HCC without overweight or insulin resistance. ${ }^{11}$ Pten conditional knockout (KO) mice on HFDs also recapitulate nonalcoholic steatohepatitis-related HCC but not metabolic syndrome. ${ }^{12}$ Melanocortin 4 receptor (MC4R) is implicated in regulation of food intake and body weight in the hypothalamic nuclei, and MC4R mutations are the most common known monogenic causes of obesity in human. ${ }^{13}$ As reported first in our previous studies ${ }^{14}$ the MC4R-KO mice exhibit obesity, insulin resistance, and dyslipidemia, and they develop steatohepatitis, liver fibrosis, and then well-differentiated HCC, suggesting this mouse model may be the best fit for reproducing the features of HCC with metabolic risk factors (HCC-MRFs).

Cross-species comparison of gene expression signatures provides a powerful approach to evaluating the biological similarity between human patients and mouse models and to elucidating the molecular system in the common phenotype. ${ }^{15}$ Although there have been several comparative studies on human and mouse metabolic liver disease, ${ }^{16} \mathrm{HCC}-\mathrm{MRF}$ are the focus in this study. Here, we performed integrative transcriptome analysis of HCC resected from human patients and MC4R-KO mice and identified a subclass of HCC closely associated with metabolic syndrome, which was characterized by overexpression of fatty acid binding protein 4 (FABP4). We investigated the clinical significance of FABP4 as a specific biomarker for this subtype and the correlation between FABP4 expression and MRFs in this study.

\section{Materials and Methods}

\section{Human Tissue Samples}

A total of 152 patients who underwent curative hepatic resection for HCC between 2006 and 2011 at Tokyo Medical and Dental University Hospital participated in the integrated gene expression microarray analysis. Fourteen adjacent liver tissues obtained from patients with metastasis of colorectal cancer who had not received chemotherapy were used as control. In addition, 106 HCC tissues surgically resected between 2012 and 2013 at the hospital were used for immunohistochemical validation analysis. With institutional review board approval, written informed consent was obtained from all patients (permission number 1080). Patients were anonymously coded in accordance with ethical guidelines, as instructed by the Declaration of Helsinki.

\section{Animal Experiments}

The MC4R-KO mice were reported in a previous study. ${ }^{14}$ Briefly, 8-week-old male mice were housed in individual cages in a temperature-, humidity-, and light-controlled room (12-hour light and 12-hour dark cycle) and allowed free access to water and HFDs and high-sucrose diets (Western diet, D12079B; Research Diets Inc., New Brunswick, NJ). At the age of 40 weeks, the animals fed ad libitum were sacrificed after intraperitoneal administration of $30 \mathrm{mg} / \mathrm{kg}$ pentobarbital anesthesia, and tumor samples were collected from the MC4R-KO mice. Normal liver tissues were also collected from the age-matched wild-type controls fed with standard diets. All animal experiments were conducted in accordance with the guidelines of the Tokyo Medical and Dental University Committee on Animal Research (number 100098).

\section{Microarray Analysis}

Total RNA was extracted from tissue specimens and cell lines by using RNeasy Protect Mini Kit (Qiagen, Tokyo, Japan). Contaminating DNA was removed by digestion with RNaseFree DNase Set (Qiagen). The integrity of the obtained RNA was confirmed by using 2100 Bioanalyzer (Agilent Technologies, Santa Clara, CA). Microarray data of human and mouse samples were analyzed as follows in accordance with the manufacturer's instructions: complementary RNA was prepared from $100 \mathrm{ng}$ of total RNA from each human sample with $3^{\prime}$ IVT Express Kit (Affymetrix, Santa Clara, CA). Hybridization and signal detection of the GeneChip Human Genome U133 Plus 2.0 Array (Affymetrix) were performed. Similarly, cyanine-3-labeled complementary RNA was prepared from total RNA for each mouse sample by using the Low Input Quick Amp Labeling kit (Agilent Technologies). Hybridization and signal detection of SurePrint G3 Mouse Gene Expression $8 \times 60 \mathrm{~K}$ Microarray Kit (G4852A; Agilent Technologies) were performed. All of the microarray data sets are deposited in GEO (https://www.ncbi. nlm.nih.gov/geo; accession number GSE102083).

\section{Integrative Analysis}

The microarray data sets of $152 \mathrm{HCC}$ and 14 normal liver tissue specimens from human individuals were normalized by using the robust multiarray average method in R statistical software version 3.0.3 (R Project, Vienna, Austria) and the Affy Bioconductor package. Normalized signal intensities of each HCC 
and normal liver sample from the MC4R-KO and wild-type mice were acquired by Feature Extraction software version 10.7.1.1 (Agilent Technologies) and then transformed into log2 base. Fold-change was calculated by using the median value of normal liver samples for each probe. Human-mouse orthologs were extracted from the HomoloGene database (build 68; ftp://ftp.ncbi.nih.gov/pub/HomoloGene/build68). Unsupervised hierarchical clustering and principle component analysis were calculated by using Ward's method in the hclust package and $\mathrm{k}$-means method in the factoextra package of $\mathrm{R}$.

\section{Cell Culture}

Human hepatic stellate cell (HSC) lines LX2 and TWNT4 were purchased from Merck Millipore (Billerica, MA) and generously gifted by Prof. Tomokazu Matsuura (The Jikei University School of Medicine, Tokyo, Japan), ${ }^{17}$ respectively. Cells were grown in Dulbecco's modified Eagle's medium (Wako, Osaka, Japan) supplemented with $10 \%$ fetal bovine serum and $1 \%$ penicillin/streptomycin (Thermo Fisher Scientific, Waltham, MA) and were cultured in a humidified incubator at $37^{\circ} \mathrm{C}$ with $5 \% \mathrm{CO}_{2}$. Culture conditions of a human $\mathrm{HCC}$ cell line $\mathrm{HuH} 7$ and a human monocyte cell line THP-1 were previously described. ${ }^{5}$

\section{Overexpression of FABP4}

For construction of a lentiviral vector that expressed FABP4, the entire coding sequence of $F A B P 4$ was amplified by using the primer pair set, 5'-TCGAGTCGACGACCATGGAGCAGAAGCTGATCTCCGAGGAGGACCTGGAACTCGAGGGATCCATGGATTACAAGGATGACGACGATAAGTGTGATGCTTTTGTAGGTAC-3' (forward, including sequences for Myc- and FLAG-tag) and 5'-TATTGCGGCCGCTTATGCTCTCTCATAAACTCTC-3' (reverse). The PCR product was digested with SalI and NotI and was cloned into the XhoI and NotI sites of the CSII-EF-MCSIRES-Puro plasmid, which was generated from the CSIIEF-MCS plasmid [a kind gift from Dr. Hiroyuki Miyoshi (Riken BioResource Center, Ibaraki, Japan)] by inserting a PstI-XbaI DNA fragment of the pIRESpuro3 plasmid (Clontech, Mountain View, CA) between the same sites, and then annealed oligonucleotides of 5'-TCGAGAATTCGCGGCCGCGGATCCTGCA-3' (forward) and 5'-CTAGGCGCCGGCGCTTAAGA-3' (reverse) between the XhoI and PstI sites were used as multiple cloning sites. HEK293T cells were transfected with the lentiviral vector, $\mathrm{pCMV} \Delta \mathrm{R} 8.2$ and pHCMV-VSV-G, kindly gifted from Dr. Irvin Chen (University of California, Los Angeles, Los Angeles, CA), by using X-tremeGENE HP DNA Transfection Reagent (SigmaAldrich, St. Louis, MO). Culture supernatants were collected and passed through $0.45-\mu \mathrm{m}$ membrane filters (Merck Millipore, Billerica, MA) 60 hours after transfection. Cells were infected for 12 hours in the supernatant that contained $10 \mu \mathrm{g} /$ $\mathrm{mL}$ polybrene (Nacalai Tesque, Kyoto, Japan) and treated with $3 \mu \mathrm{g} / \mathrm{mL}$ puromycin (Thermo Fisher Scientific) for selection 2 days after infection.

Table 1 Primer Sequences Used for Quantitative RT-PCR

\begin{tabular}{|c|c|c|c|}
\hline Gene name & Primer & Sequence & Product size, bp \\
\hline \multirow[t]{2}{*}{ FABP4 } & Forward & 5'-ACTGGGCCAGGAATTTGACG-3' & 183 \\
\hline & Reverse & 5'-CTCGTGGAAGTGACGCCTT-3' & \\
\hline \multirow[t]{2}{*}{ SPARCL1 } & Forward & 5'-TTGCTCAAAGGCCACTTTCG-3' & 109 \\
\hline & Reverse & 5'-CCAGGCTACAGTCCAGGCT-3' & \\
\hline \multirow[t]{2}{*}{ DKK3 } & Forward & $5^{\prime}-$ ACGGTAGCACCTGACAACAC- $3^{\prime}$ & 99 \\
\hline & Reverse & 5'-ATGGTGGGAATCGTCTTCTGT-3' & \\
\hline \multirow[t]{2}{*}{ Sparcl1 } & Forward & 5'-CAGCTCTCAACTACCCTCAGG-3' & 148 \\
\hline & Reverse & $5^{\prime}$-ACCTCAGAGGACGTTTTAGCA-3' & \\
\hline \multirow[t]{2}{*}{ Dkk3 } & Forward & $5^{\prime}$-GGCAATCCCGACAAGTACAAG-3' & 126 \\
\hline & Reverse & 5'-TGGTTTTCTATGTCTGCTGTAGC-3' & \\
\hline CXCL3 & Forward & $5^{\prime}-\mathrm{CGCCCAAACCGAAGTCATAG-3^{ \prime }}$ & 109 \\
\hline CXCL6 & Reverse & 5'-GCAGTTTACCAATCGTTTTGGGG-3' & \\
\hline \multirow[t]{2}{*}{ CXCL8 } & Forward & 5'-TTTTGCCAAGGAGTGCTAAAGA-3' & 194 \\
\hline & Reverse & $5^{\prime}$-АAСССТCTGCACCCAGTTTTC-3' & \\
\hline \multirow[t]{2}{*}{ IL1A } & Forward & 5'-TGGTAGTAGCAACCAACGGGA-3' & 215 \\
\hline & Reverse & $5^{\prime}$-ACTTTGATTGAGGGCGTCATTC-3' & \\
\hline \multirow[t]{2}{*}{ IL6 } & Forward & 5'-GTGACGGTGTTGATGGTAAGAT-3' & 94 \\
\hline & Reverse & 5'-AGCTCCACAGAGTGTTCCTTG-3' & \\
\hline \multirow[t]{2}{*}{ IL33 } & Forward & 5'-АСТCACСTCTTCAGAACGAATTG-3' & 149 \\
\hline & Reverse & 5'-CCATCTTTGGAAGGTTCAGGTTG-3' & \\
\hline
\end{tabular}




\section{Western Blot Analysis}

Total protein was extracted from cells and Western blot analysis was performed as described previously. ${ }^{18}$ Primary antibodies used were anti-FABP4 (dilution 1:500; ab13979; Abcam, Cambridge, UK) and anti- $\alpha$-tubulin (dilution 1:200; TU-02; Santa Cruz Biotechnology, Santa Cruz, CA) antibodies.

\section{Immunohistochemical Analysis}

Formalin-fixed and paraffin-embedded tissues of human HCCs were used for immunohistochemistry. Mouse liver tissues were fixed overnight in $4 \%$ paraformaldehyde and embedded in paraffin. Tissue sections $(3 \mu \mathrm{m})$ were stained with an automated immunostainer (Discovery XT; Ventana Medical Systems, Tucson, AZ) by using heat-induced epitope retrieval and a standard diaminobenzidine detection kit. The following primary antibodies were used: antiFABP4 (dilution 1:500), anti-Dickkopf-related protein 3 (DKK3; dilution 1:500; AF1118; R\&D Systems, Minneapolis, MN), anti-secreted protein acidic and rich in cysteine-like protein 1 (SPARCL1; dilution 1:500; GTX12308; GeneTex, Irvine, CA), anti- $\alpha$-smooth muscle

\section{A}

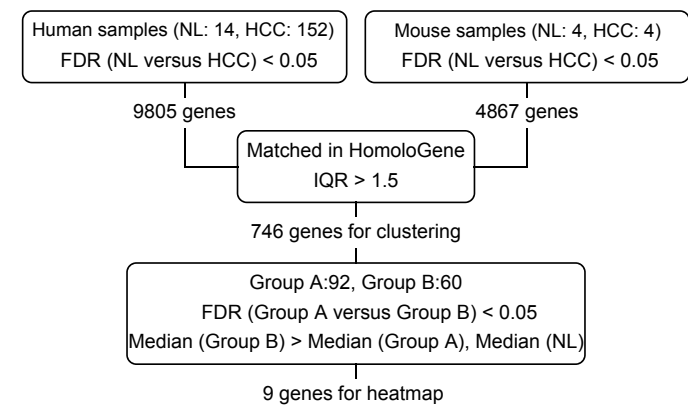

C

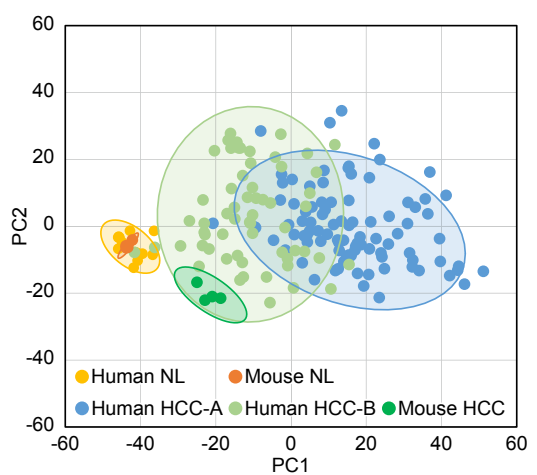

actin ( $\alpha$-SMA; dilution 1:100; M08512; Dako, Glostrup, Denmark), anti-CD68 (dilution 1:500; M0876; Dako), and anti-F4/80 (dilution 1:500; 122601; BioLegend, San Diego, CA) antibodies. All tissue sections were counterstained with hematoxylin. According to the previous report of FABP4 immunostaining, ${ }^{19}$ the staining patterns were determined as four proportion scores: none $(0)$, low $(1+)$, which indicated no hot spots, but rare, scattered FABP4-positive cells; intermediate $(2+)$, which indicated the presence of less than two hot spots with or without scattered FABP4 cells; and high $(3+)$, which indicated the presence of two or more hot spots with or without scattered FABP4 cells. In addition, the staining intensity of FABP4 was examined as the following three intensity scores: negative $(0)$, weak $(1+)$, and strong $(2+)$. The total score was obtained by summing the proportion and intensity scores, and then FABP4 expression patterns were divided into two groups, FABP4-high (total score $>3$ ) and -low (total score $\leq 3$ ).

For evaluation of FABP 4 and $\alpha$-SMA expression, double immunofluorescence analysis was performed by using the secondary antibodies Alexa Fluor 488 goat anti-rabbit $\mathrm{IgG}$ (dilution 1:500; A-11008; Life Technologies, Carlsbad, CA) and Alexa Fluor 568 goat anti-mouse IgG (dilution 1:500; A-11004; Life Technologies), respectively. After mounting

B

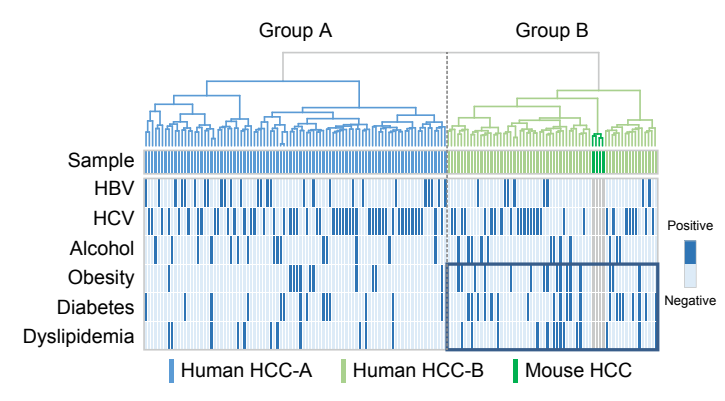

D

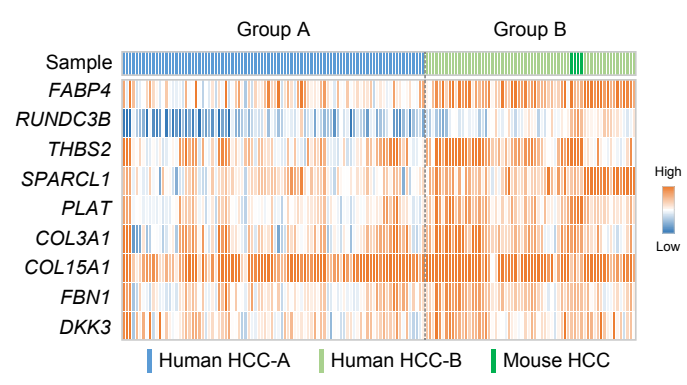

Figure 1 Integrative transcriptome analysis of human and mouse hepatocellular carcinoma (HCC) with metabolic risk factors (MRFs). A: 0verview of the cross-species comparative analysis to identify candidate genes associated with HCC-MRF. B: Dendrogram of unsupervised hierarchy clustering analysis of the 746 candidate orthologous genes in HCC from human patients and melanocortin 4 receptor-knockout (MC4R-KO) mice. Clinical features of the human patients are shown along the dendrogram. Group A was characterized by hepatitis B virus (HBV) infection $(P=0.030)$ and Group B with MRFs, that is, obesity, diabetes, and dyslipidemia $(P=0.029,0.010$, and 0.076 , respectively). C: Plot of principle component analysis. Ellipses indicate groups of human and mouse normal liver and HCC. D: Heatmap of candidate genes extracted by the strategy illustrated in A. Samples are ordered according to the clustering analysis in B. $n=152$ human patients (B); $n=4$ MC4R-KO mice (B); $n=9$ candidate genes (D). FDR, false discovery rate; HCV, hepatitis C virus; IQR, interquartile range; $\mathrm{NL}$, normal liver; $\mathrm{PC}$, principle component. 
A

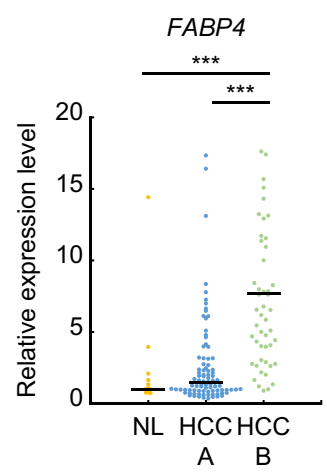

B

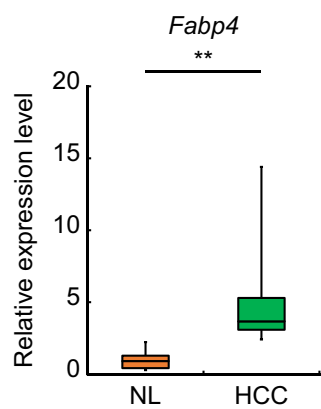

Human

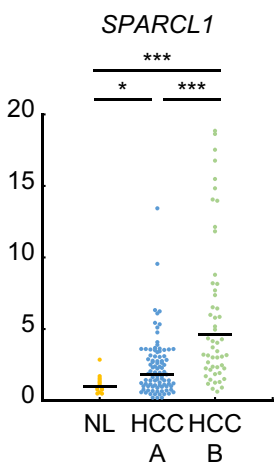

A B

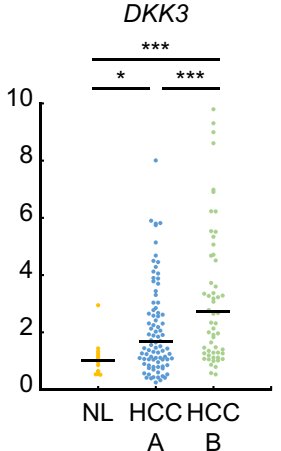

A B

C

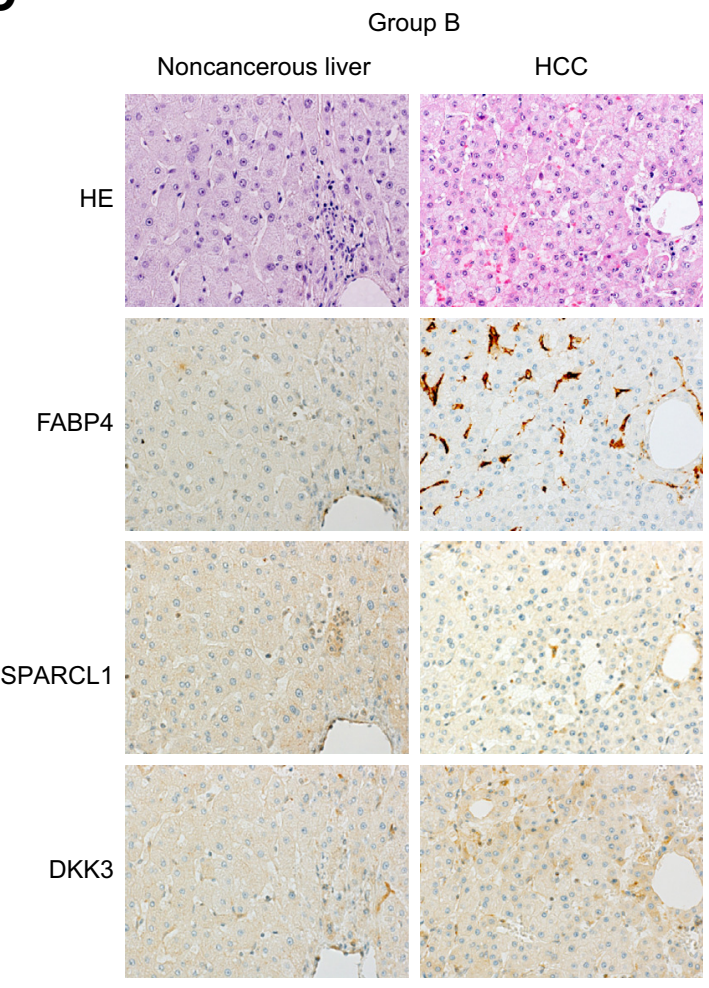

Figure 2 Expression analysis of fatty acid binding protein 4 (FABP4), Dickkopf-related protein 3 (DKK3), and secreted protein acidic and rich in cysteine-like protein 1 (SPARCL1) in hepatocellular carcinoma (HCC). A: Relative expression levels of FABP4, SPARCL1, and DKK3 in normal liver, HCC-A, and HCC-B samples at the mRNA level. The value of each sample was relative to the median value of the normal liver group. B: Relative expression levels of Fabp4, Sparcl1, and Dkk3 in normal livers of wild-type mice and HCC samples of the melanocortin 4 receptor-knockout (MC4R-KO) mice at the mRNA level. C: Immunohistochemical staining of FABP4, SPARKL1, and DKK3. Serial sections of the samples were stained with hematoxylin and eosin. Horizontal lines indicate the median (A). Box and whisker plot shows the interquartile range with median, 25th and 75th percentile, and minimum and maximum values (B). $n=14$ normal liver samples $n=92 \mathrm{HCC}-\mathrm{A}$ samples, and $n=60 \mathrm{HCC}-\mathrm{B}$ samples $(\mathbf{A}) ; n=6$ normal livers of wild-type mice and $n=7 \mathrm{HCC}$ samples of MC4R-K0 mice (B). ${ }^{*} P<0.05,{ }^{* *} P<0.01$, and ${ }^{* *} P<0.001$ (Kruskal-Wallis test with Steel-Dwass post hoc test or $U$-test). Original magnification, $\times 200$ (C). HE, hematoxylin and eosin; NL, normal liver.

with DAPI, the slides were viewed with a fluorescent microscope (Carl Zeiss, Oberkochen, Germany).

\section{Immunocytochemical Analysis}

Cells were fixed and stained as described previously. ${ }^{18} \mathrm{~A}$ primary antibody against p65 NF-кB (dilution 1:200; 8242; Cell Signaling Technology, Danvers, MA) was used.

\section{Quantitative RT-PCR}

Total RNA was extracted from cells, and quantitative RTPCR was performed as described previously. ${ }^{18}$ The primer sequences and their real-time quantitative PCR conditions are shown in Table 1.

\section{Treatment with NF- $\kappa \mathrm{B}$ Inhibitor}

Cells were incubated with Dulbecco's modified Eagle's medium that contained SN50 (Merck Millipore), a cellpermeable peptide antagonist of NF- $\kappa \mathrm{B}$ nuclear translocation, at a concentration of 0 or $50 \mu \mathrm{g} / \mathrm{mL}$. Nuclear translocation of
$\mathrm{NF}-\kappa \mathrm{B}$ and gene expression change were assessed after 2 and 12 hours of treatment, respectively.

\section{Cell Proliferation Assay}

Confluent LX2 cells were grown in 10-cm dishes for 3 days, and culture supernatants were collected and passed through $0.45-\mu \mathrm{m}$ membrane filters (Merck Millipore). The $\mathrm{HuH} 7$ cells were then plated at a density of $1 \times 10^{3}$ cells per well in 96-well plates with the conditioned medium and were counterstained for nuclei with Hoechst 33342 solution (Dojindo, Kumamoto, Japan), and the number was estimated with IN Cell Analyzer 2000 (GE Healthcare, Buckinghamshire, UK).

\section{Cell Migration Assay}

The double-chamber migration assay was performed by using a Transwell chamber (24-well plate, 8 - $\mu \mathrm{m}$ pores; BD Biosciences, San Jose, CA). In migration assays for the LX2 cells, after the lower chambers were filled with $0.8 \mathrm{~mL}$ of culture medium, cells were seeded at a density of $1 \times 10^{4}$ cells per well onto the upper chambers with $0.3 \mathrm{~mL}$ of serum-free medium 
A

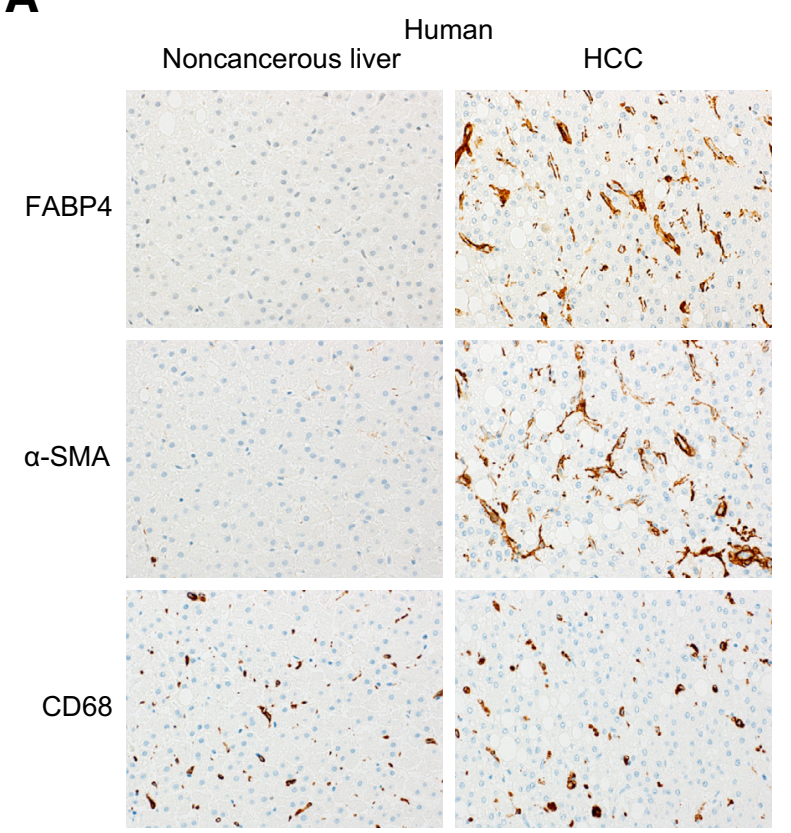

C
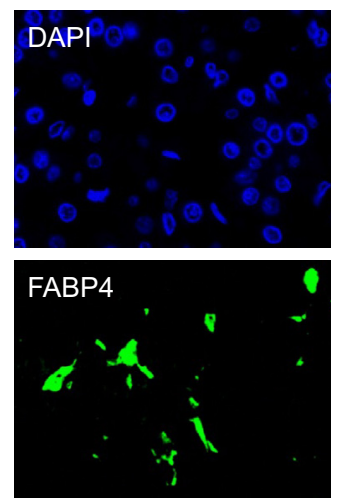

B

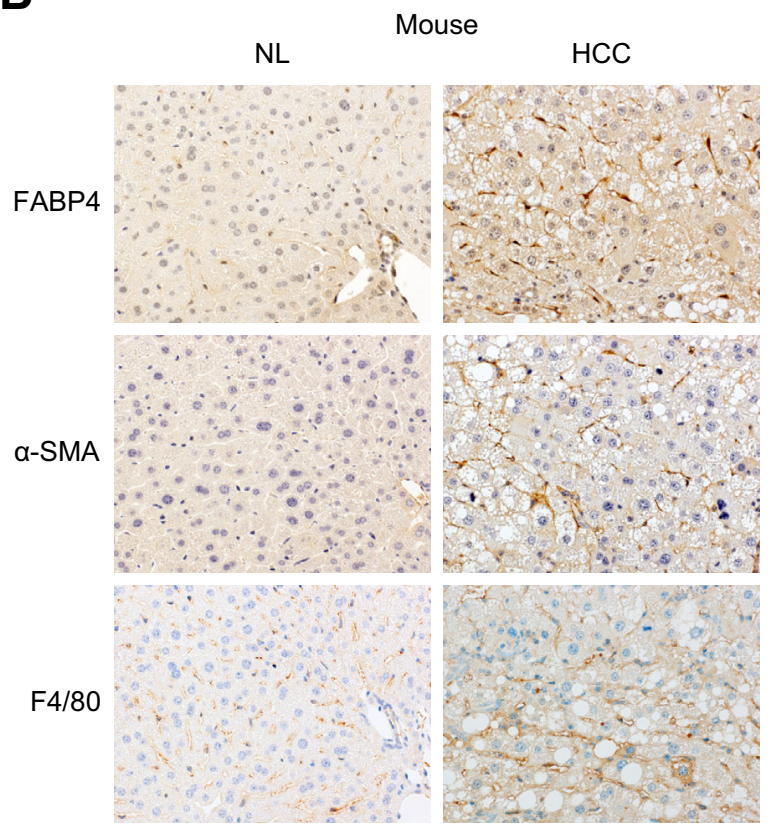

D
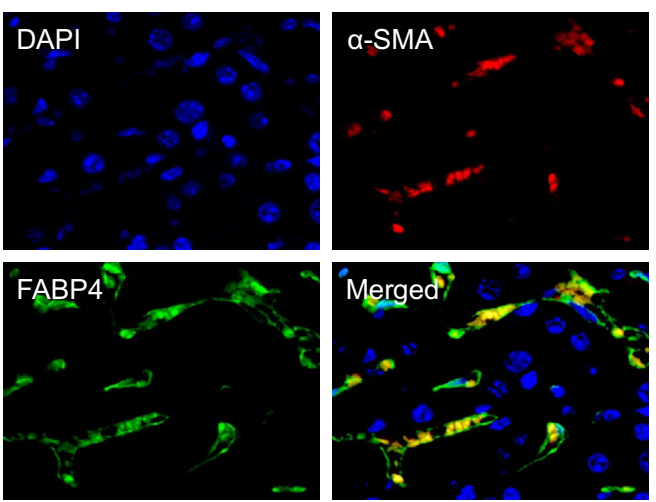

Figure 3 Fatty acid binding protein 4 (FABP4) expression in activated hepatic stellate cells (HSCs). A: Immunohistochemical staining of FABP4, $\alpha$-smooth muscle actin $(\alpha-S M A)$, and CD68 in human hepatocellular carcinoma $(H C C)$ tissues and adjacent noncancerous liver tissues. B: Immunohistochemical staining of FABP4, $\alpha$-SMA, and F4/80 in HCC tissues of the melanocortin 4 receptor-knockout (MC4R-K0) mice and normal liver (NL) tissues of wild-type mice. The MC4R-KO mice were fed with high-fat and high-sucrose diets from age 8 to 40 weeks. C and D: Double-labeling immunofluorescence for FABP4 (green) and $\alpha$ SMA (red) in HCC tissues of human patients (C) and the MC4R-KO mice (D). Nuclei were stained with DAPI (blue). Original magnification, $\times 200$.

and were incubated at $37^{\circ} \mathrm{C}$ for 24 hours. In the same way, after the LX2 cells were plated at a density of $7.5 \times 10^{4}$ cells per well in the lower chambers, the phorbol 12-myristate 13acetate-primed macrophage-like THP-1 cells were seeded at a density of $5 \times 10^{4}$ cells per well onto the upper chambers. The cells on the upper surface of the filters were removed by using cotton wool swabs. The remaining cells were then fixed with $100 \%$ methanol and stained with Giemsa solution, and the number of cells migrating or infiltrating into the lower surface was counted in 10 randomly selected high-magnification fields $(\times 100)$ for each sample.

\section{Statistical Analysis}

Statistical analyses were performed with SPSS version 23.0 (SPSS, Inc., Chicago, IL). Data are presented as means \pm SD.
Two-sided Welch's $t$-tests were used to analyze for differences between continuous values of two independent groups. The $\chi^{2}$ test or Fisher's exact test was applied to analyze categorical variables. $P<0.05$ was considered statistically significant. As previously described, ${ }^{18}$ gene set enrichment analysis was performed with the Molecular Signatures Database gene sets (H: hallmark gene sets, $\mathrm{C} 2$ : chemical and genetic perturbations, and C3: transcription factor targets; version 5.0) provided from the Broad Institute (Cambridge, MA).

\section{Results}

Integrative Transcriptome Analysis of Human and Mouse HCC with MRFs

Gene expression profiles of HCC samples from 152 human patients and four MC4R-KO mice were characterized 
A

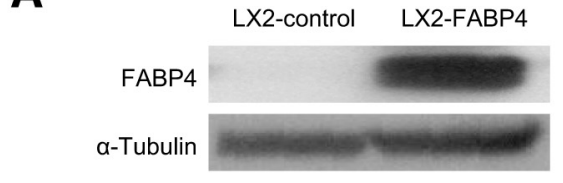

B
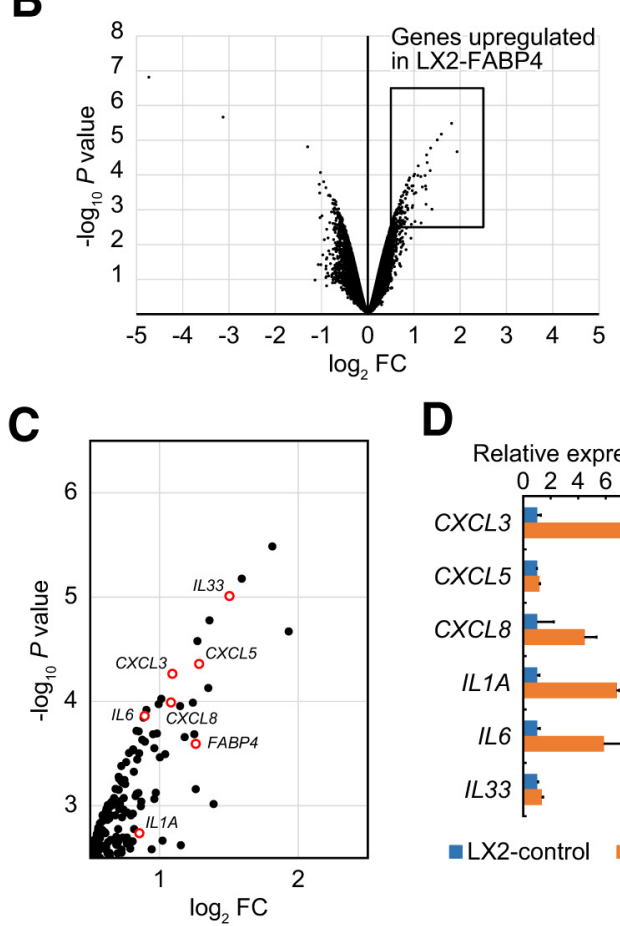

$\mathbf{E}$
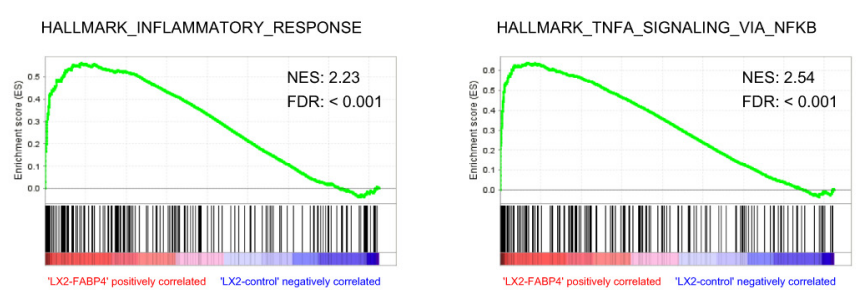

HINATA_NFKB_TARGETS_KERATINOCYTE_UP
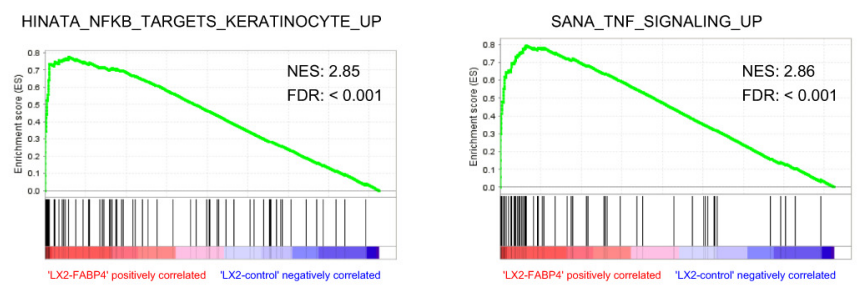

Delative expression level

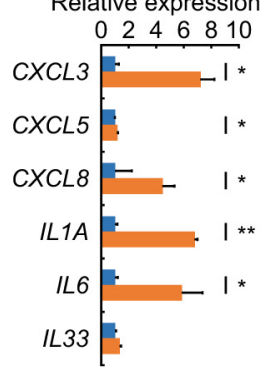

- LX2-control $\quad$ LX2-FABP4
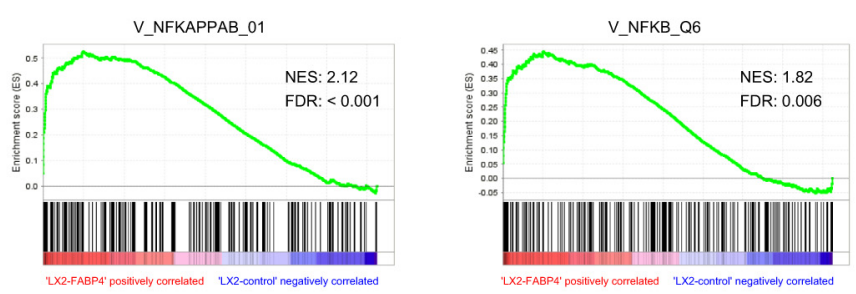

Figure 4 Gene expression analysis of fatty acid binding protein 4 (FABP4)-overexpressing LX2 cells. A: Western blot analysis of FABP4. The LX2-FABP4 cells were stable transformants of FABP4 overexpression established from the LX2 human hepatic stellate cells (HSCs). $\alpha$-Tubulin is used as an internal control. B: Volcano plot of differentially expressed genes between the LX2-FABP4 and control cells. Boxed area shows genes significantly up-regulated in the LX2-FABP4 (fold-change $\geq 2$ and $P<0.005$ ). C: Representative image of genes up-regulated in the LX2-FABP cells. Red circles indicate proinflammatory cytokines. D: Relative expression levels of the proinflammatory cytokines in LX2-FABP4 cells. E: Enrichment plots of gene sets associated with inflammatory response. Data are expressed as means $\pm \mathrm{SD}$ (D). $n=3$ independent experiments $(\mathbf{D}) .{ }^{*} P<0.05,{ }^{*} P<0.01$ (Welch's $t$-test). FC, fold-change; FDR, false discovery rate; NES, normalized enrichment score; TNFA, tumor necrosis factor $\alpha$.

according to the strategy shown in Figure 1A. First, unsupervised hierarchical clustering (Figure 1B) and principle component analysis (Figure 1C) of 746 differentially expressed orthologous genes identified two distinctive groups, $\mathrm{A}$ and $\mathrm{B}$, which were critically associated with causative factors (Supplemental Table S1); Group A included more HBV carriers $(P=0.045$, Fisher's exact test), whereas Group B was composed of patients with MRFs, that is, obesity, diabetes, and dyslipidemia $(P=0.029,0.010$, and 0.076 , Fisher's exact test). No apparent difference of HCV infection or alcohol intake was found between Groups A and B. Notably, all of the HCC specimens dissected from the MC4R-KO mice were classified into Group B. Taken together, these results suggested that Group B could represent HCC-MRFs and that the MC4R-KO mice could molecularly recapitulate this subtype. These findings were retrospectively supported by the previous studies that the development of HCC in patients with MRFs typically occurred at an older age than patients with other liver disease $^{20}(P=0.003$, Welch's $t$-test $)$ and that metabolicrelated gene sets were strikingly enriched in Group B
(Supplemental Table S2 and Supplemental Figure S1). According to the criteria (Figure 1A), nine genes were identified as commonly overexpressed in human and mouse HCC-MRFs (Figure 1D). Among these genes, FABP4, SPARCL1, and $D K K 3$ have been reported to be closely related not only to metabolic disorders with obesity and diabete ${ }^{21-23}$ but also to cancer progression. ${ }^{24-26}$ Considering the expression levels (Figure 1D) and these previous studies concerned with the three genes, ${ }^{21-26}$ FABP4, SPARCL1, and DKK3 were studied further.

Expression of FABP4, SPARCL1, and DKK3 at the RNA and Protein Levels

By using the microarray data of 14 normal liver tissues and 152 primary HCC samples, HCC of Group B (HCC-B) exhibited significantly increased expression of FABP4, SPARCL1, and DKK3 compared with normal liver and HCC of Group A (HCC-A) (Figure 2A). Quantitative RT-PCR analysis also indicated that the expression levels of all of 


\section{A}

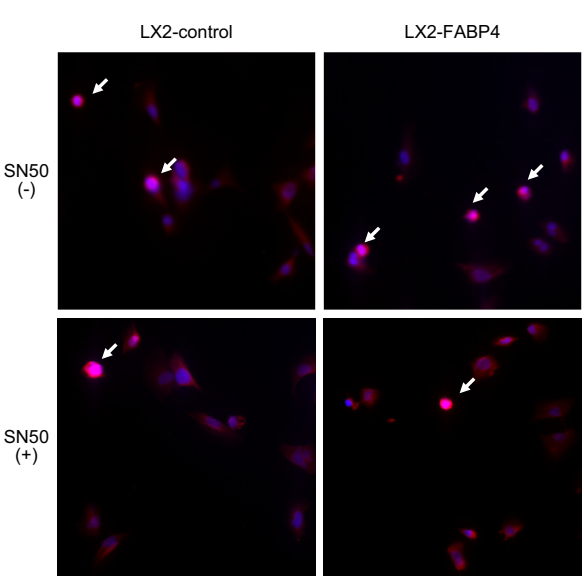

B
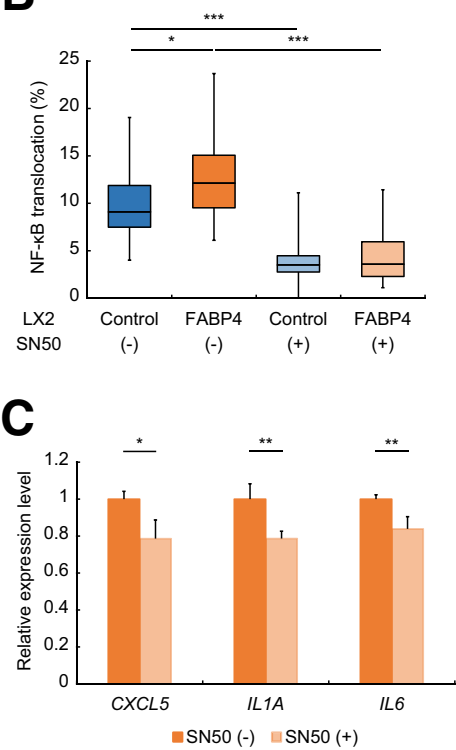

Figure 5 Activation of NF- $\mathrm{KB}$ pathway by fatty acid binding protein 4 (FABP4) overexpression in LX2 cells. A: Immunofluorescence analysis of the LX2-FABP4 and LX2-control cells cultured with the NF- $\kappa B$ inhibitor, SN50, for 2 hours. Cells were stained with p65 NF- $\kappa B$ (red) antibody and nuclei were costained with DAPI (blue). Nuclear staining of p65 NF- $\kappa \mathrm{B}$ is shown by arrows. B: Nuclear translocation of p65 NF- $\mathrm{BB}$ in the LX2-FABP4 cells with and without SN50 treatment. C: Relative expression levels of proinflammatory cytokines in the LX2-FABP4 cells with and without SN50 by real-time quantitative PCR. Data are expressed as means \pm SD (B and C). $n=3$ independent experiments (C). ${ }^{*} P<0.05,{ }^{*} * P<0.01$, and $* * * P<0.001$ (Welch's $t$-test). Original magnification, $\times 200($ A).

the three genes were more up-regulated in HCC tissues of the MC4R-KO mice fed with HFDs and high-sucrose diets than normal liver of wild-type mice (Figure 2B). Next, protein expression was examined by immunohistochemical analysis by using 14 HCC-A and 8 HCC-B samples (Figure 2C, Supplemental Figure S2, and Supplemental Figure S3). SPARCL1 and DKK3 were positive in $12.5 \%$ and $37.5 \%$ of the HCC-B cases, respectively, and in $14.3 \%$ and $21.4 \%$ of the HCC-A cases, respectively, suggesting no difference at the protein levels between the two groups $(P=1.000$ and 0.624 , Fisher's exact test). In contrast, strong FABP4 immunoreactivity was frequently detected in the tumor area of the HCC-B

A

LX2 $1 \times 10^{4}$ cells
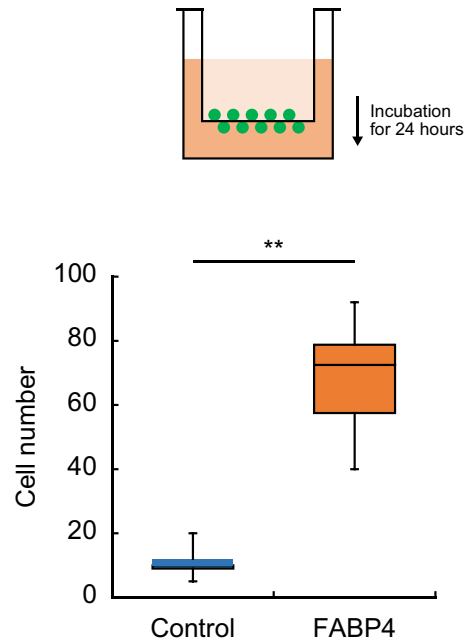

LX2-control

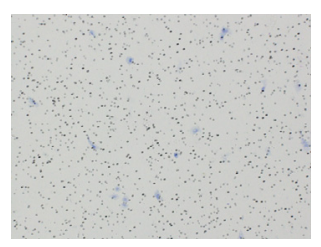

LX2-FABP4

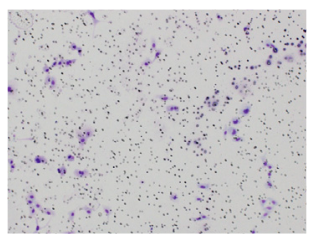

samples $(87.5 \%)$ compared with the HCC-A samples $(28.6 \%)$, which was statistically significant $(P=0.023$, Fisher's exact test). Of note, spindle-shaped cells overexpressed FABP4 in the stromal region of human HCC tissues but not in the surrounding noncancerous tissues, including cirrhotic liver or dysplastic nodules.

\section{Localization of FABP4 Protein in Human and Mouse HCC Tissues}

Recent studies have reported that FABP4 is a marker for adipocyte-like quiescent $\mathrm{HSCs}^{27}$ and macrophages during

B

THP1 $5 \times 10^{4}$ cells

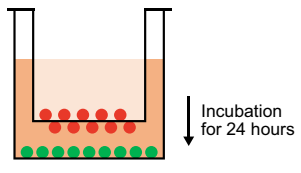

LX2 $7.5 \times 10^{4}$ cells

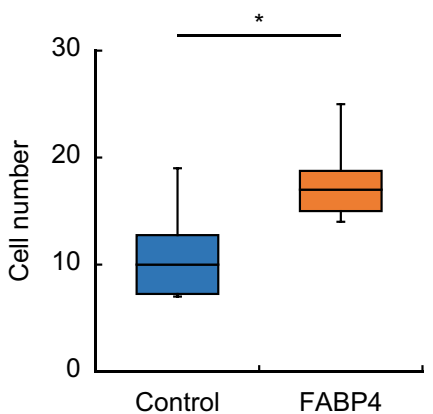

THP1 / LX2-control

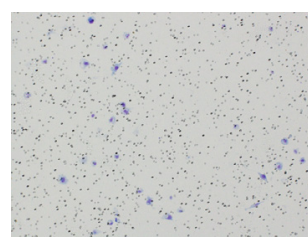

THP1 / LX2-FABP4

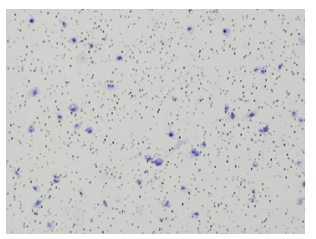

Figure 6 Biological roles of fatty acid binding protein 4 (FABP4) overexpression in LX2 cells. A: Transwell migration assay for the LX2 cells. B: Transwell migration assay for the differentiated THP1 cells with conditioned medium derived from the LX2 cells. Each left upper panel displays the outline of the assay. The numbers of infiltrating cells are estimated in the left lower panels. Representative images are shown in the right panels. Data are expressed as means $\pm \mathrm{SD} .{ }^{*} P<0.05,{ }^{* *} P<0.01$ (U-test). Original magnification, $\times 200$. 

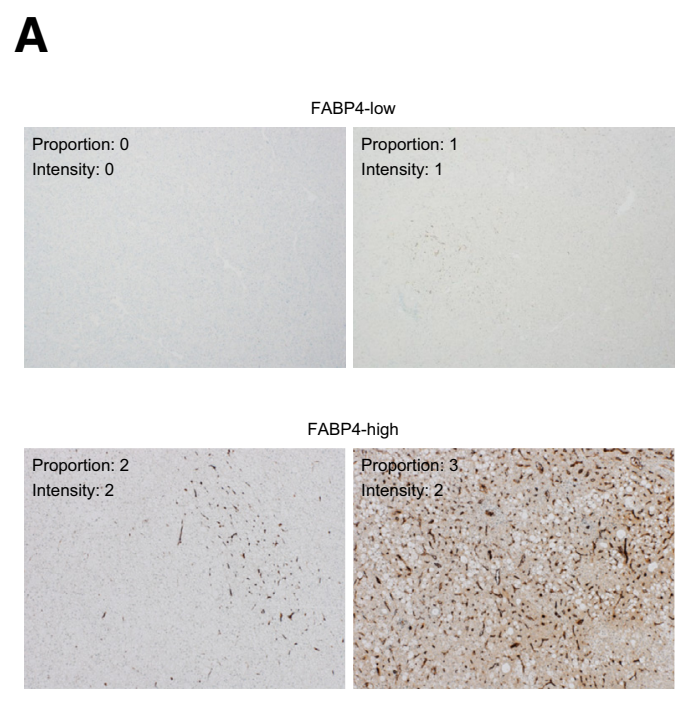

B

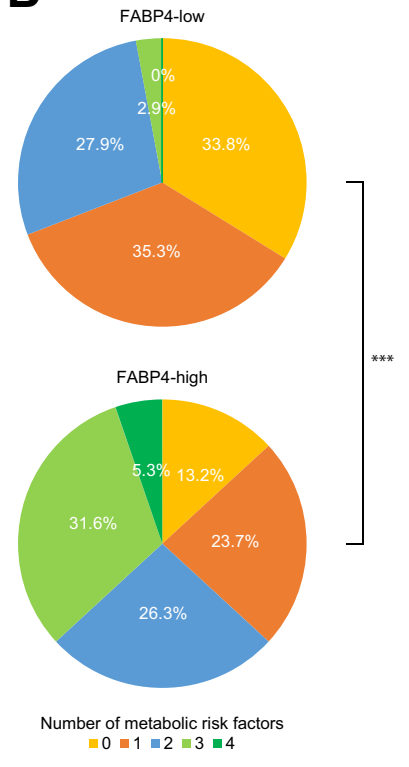

Figure 7 Validation analysis of fatty acid binding protein 4 (FABP4) expression in human primary hepatocellular carcinoma (HCC) tissues by immunohistochemistry. A: Representative FABP4 expression patterns in HCC tissues. FABP4 expression was scored on the basis of the proportion and intensity (Materials and Methods) and was divided into FABP4-high and FABP4-low groups. B: Pie charts of the number of metabolic risk factors (obesity, diabetes, hypertension, and dyslipidemia) in the FABP4-high and FABP4-low groups. ${ }^{* *} P<0.001$ (Fisher's exact test). Original magnification, $\times 200($ A). cirrhosis. ${ }^{28}$ To determine which types of cells were FABP4positive, we performed additional immunohistochemical analysis of markers of activated HSCs and macrophages, including Kupffer cells, that is, $\alpha$-SMA and human CD68 or mouse F4/80, respectively. The expression patterns of FABP4 were overlapped to those of $\alpha$-SMA, not CD68, possibly indicating that activated HSCs aberrantly expressed FABP4 (Figure 3A). Although distributed in adjacent liver tissues, activated HSCs overexpressed FABP4 specifically in tumor tissues of human HCC-MRFs. Similar expression profiles of FABP4 and $\alpha$-SMA were observed in HCCs of the MC4R-KO mice (Figure 3B). These findings were confirmed by immunofluorescent costaining of FABP4 and $\alpha$-SMA in intratumoral-activated HSCs within human and mouse HCC tissues (Figure 3, C and D).

\section{Relationship between FABP4 Expression in HSCs and Inflammatory Response}

For analysis of the molecular effects of FABP4 expression in HSCs, we established a subline of the LX2 human HSC cell line overexpressing FABP4, which was termed as LX2FABP4 (Figure 4A). Genome-wide expression analysis with DNA microarrays revealed that the expression levels of proinflammatory cytokines, such as CXCL3, CXCL5, CXCL8, IL-1A, and IL-6, were more highly up-regulated in the LX2-FABP4 cells than those in the control cells (Figure 4, B and C). These expression changes were validated by real-time quantitative PCR (Figure 4D). We also established subclones constitutively expressing FABP4 from another human HSC cell line TWNT4 and observed that the mRNA expression levels of cytokines, including CXCL3, CXCL8, and IL-1A, were up-regulated in the FABP4-overexpressing TWNT4 cells (Supplemental
Figure S4). Gene set enrichment analysis demonstrated that gene signatures involved in inflammatory response and in particular tumor necrosis factor $\alpha / \mathrm{NF}-\kappa \mathrm{B}$ pathway were extremely augmented in the LX2-FABP4 cells (Figure 4E and Supplemental Table S3). As expected from the computational prediction, the nuclear staining of p65 NF- $\kappa \mathrm{B}$ was significantly increased in the LX2-FABP4 cells compared with the control cells (Figure 5, A and B). Indeed, treatment with the NF- $\kappa \mathrm{B}$ inhibitor SN50 suppressed the nuclear translocation of p65 NF- $\kappa \mathrm{B}$ in the LX2-FABP4 cells down to the control level (Figure 5, A and B) and subsequently down-regulated the expression levels of proinflammatory cytokines CXCL5, IL-1A, and IL-6 (Figure 5C). FABP4 overexpression also enhanced migration activity of the LX2 cells (Figure 6A).

The biological effects of FABP4-expressing HSCs on cancer cells and tumor microenvironment were examined next. When a human HCC cell line HuH7 was cultured in conditioned medium derived from the LX2-control and -FABP4 cells, no apparent difference of proliferative activity was found between them (Supplemental Figure S5). In contrast, Boyden chamber assays strikingly elucidated that the LX2-FABP4 cells could recruit human THP-1 macrophages, probably due to the secretion of cytokines (Figure 6B). These data suggested that FABP4-expressing HSCs could indirectly contribute to hepatocarcinogenesis by modulating inflammatory response.

\section{Validation Study for Clinicopathologic Significance of FABP4 Expression in Human HCC Tissues}

The relationship between clinicopathologic factors and FABP4 expression was examined by immunohistochemical analysis of an additional $106 \mathrm{HCC}$ tissues. High expression of 
Table 2 Validation Study for Clinicopathologic Significance of FABP4 Expression in HCC Tissues $(n=106)$

\begin{tabular}{|c|c|c|c|}
\hline \multirow[b]{2}{*}{ Clinicopathologic factor } & \multicolumn{2}{|l|}{ FABP4 } & \multirow[b]{2}{*}{$P$} \\
\hline & $\begin{array}{l}\text { Low } \\
(n=68)\end{array}$ & $\begin{array}{l}\text { High } \\
(n=38)\end{array}$ & \\
\hline Sex & & & 1.000 \\
\hline Male & 49 & 28 & \\
\hline Female & 19 & 10 & \\
\hline Age & 67.9 & 72.4 & $0.021 *$ \\
\hline HBV & 15 & 1 & $0.009^{\dagger}$ \\
\hline $\mathrm{HCV}$ & 31 & 17 & 1.000 \\
\hline Alcohol & 19 & 12 & 0.824 \\
\hline NBNC & 22 & 20 & 0.062 \\
\hline NBNCNA & 10 & 13 & $0.027^{*}$ \\
\hline Obesity & 15 & 21 & $0.001^{*}$ \\
\hline Diabetes & 13 & 16 & $0.014^{*}$ \\
\hline Hypertension & 37 & 27 & 0.103 \\
\hline Dyslipidemia & 3 & 9 & $0.008^{*}$ \\
\hline Child-Pugh A/B & $64 / 4$ & $36 / 2$ & 1.000 \\
\hline $\mathrm{NL} / \mathrm{CH} / \mathrm{LC}$ & $12 / 22 / 34$ & $6 / 18 / 14$ & 0.225 \\
\hline NASH & 0 & 3 & $0.046^{*}$ \\
\hline Plt $\left(<10 \times 10^{4} / \mu \mathrm{L}\right)$ & 15 & 6 & 0.612 \\
\hline PT $(<80 \%)$ & 15 & 5 & 0.310 \\
\hline Alb $(<3.5 \mathrm{~g} / \mathrm{dL})$ & 11 & 6 & 1.000 \\
\hline AST (>40 IU/I) & 24 & 12 & 0.831 \\
\hline $\operatorname{ALT}(>40 \mathrm{IU} / \mathrm{I})$ & 20 & 8 & 0.491 \\
\hline$\gamma-\mathrm{GTP}(>50 \mathrm{IU} / \mathrm{I})$ & 29 & 20 & 0.417 \\
\hline CRP $(>0.3 \mathrm{mg} / \mathrm{dL})$ & 17 & 13 & 0.371 \\
\hline T-bil (>1 mg/dL) & 21 & 6 & 0.107 \\
\hline ICG15 (>15\%) & 35 & 15 & 0.311 \\
\hline $\operatorname{AFP}(>20 \mathrm{ng} / \mathrm{mL})$ & 31 & 13 & 0.307 \\
\hline $\begin{array}{l}\text { PIVKA-II } \\
\qquad(>40 \mathrm{mAU} / \mathrm{mL})\end{array}$ & 42 & 20 & 0.414 \\
\hline Tumor size $(\geq 5 \mathrm{~cm})$ & 16 & 11 & 0.643 \\
\hline Tumor number $(\geq 2)$ & 11 & 13 & 0.052 \\
\hline $\begin{array}{l}\text { Differentiation } \\
\text { (wel/mod-por) }\end{array}$ & $29 / 39$ & $16 / 22$ & 1.000 \\
\hline
\end{tabular}

*Positive correlation.

${ }^{\dagger}$ Negative correlation.

AFP, alpha-fetoprotein; Alb, albumin; Alcohol, alcohol consumption $\geq 60$ $\mathrm{g} / \mathrm{d}$; ALT, alanine aminotransferase; AST, aspartate aminotransferase; AU, arbitrary unit; $\mathrm{CH}$, chronic hepatitis; CRP, C-reactive protein; FABP4, fatty acid binding protein $4 ; \gamma$-GTP, $\gamma$-glutamyl transpeptidase; HBV, hepatitis $B$ virus positive; $\mathrm{HCC}$, hepatocellular carcinoma; $\mathrm{HCV}$, hepatitis $\mathrm{C}$ virus positive; ICG15, indocyanine green retention test; LC, liver cirrhosis; mod-por, moderate to poor; NASH, nonalcoholic steatohepatitis; NBNC, non-B, non-C type; NBNCNA, non-B, non-C, nonalcoholic type; NL, normal liver; Obesity, body mass index $\geq 25 \mathrm{~kg} / \mathrm{m}^{2}$; PIVKA-II, protein induced by vitamin $\mathrm{K}$ absence; Plt, platelet; PT, prothrombin; T-bil, total bilirubin; wel, well.

FABP4 was detected in the intratumoral HSCs in 38 cases $(35.8 \%)$ (Figure 7A, and Supplemental Figure S6). The FABP4-high group was significantly correlated with aging, non-HBV, non-HBV/non-HCV/nonalcoholic type, and several MRFs $\left(P<0.05, \chi^{2}\right.$ test $)$ Table 2$)$, essentially coincident with the test study of hierarchical clustering (Figure 1B). Finally, the relationship was evaluated between overexpression of FABP4 and accumulation of four MRFs: obesity, diabetes, hypertension, and dyslipidemia (Figure 7B).
The population without any risk factors accounted for $33.8 \%$ in the patients with the FABP4-low HCC, but only for $13.2 \%$ in the patients with the FABP4-high. Of note, $36.9 \%$ of the FABP4-high group carried three or more risk factors and $2.9 \%$ of the FABP4-low group $(P<0.001$, Fisher's exact test), indicating that as the number of MRFs increased so did FABP4 expression in HCC.

\section{Discussion}

Cross-species comparative analysis of gene expression patterns is useful for not only comprehensively evaluating the molecular similarity between human and mouse cancer but also precisely classifying human cancer in consideration of genetic, pathologic, and clinical features. ${ }^{29,30}$ By characterizing gene signatures of HCC samples from human patients and seven mouse models, Lee et al ${ }^{31}$ confirmed two predefined subclasses of human HCC were well separated from each other as well as elucidated that the Myc/Tgfatransgenic mice recapitulated the poorer survival subgroup, whereas the $M y c-, E 2 f-$, and $M y c / E 2 f$-transgenic mice did better. In this study, we investigated a mouse model of HCC-MRFs, the MC4R-KO mouse, which is representative of metabolic syndrome-associated liver disease (Figure 1A). Hierarchy clustering and principle component analysis of gene signatures of human and mouse HCC demonstrated the molecular and causative similarity between HCC-MRFs of human patients and the MC4R-KO mice (Figure 1B). This proof-of-concept study identified FABP4 as a commonly expressed gene associated with HCC-MRFs.

FABP4, originally isolated from adipocytes and known as adipocyte protein 2 , is one of the essential regulators of metabolic syndrome. ${ }^{21}$ Metabolically induced proinflammatory responses are suppressed by depletion of FABP4, indicating its function not only as a lipid chaperone but also as a mediator of inflammation. ${ }^{32}$ In addition to fatty acids, FABP4 interacts with leukotriene A4, CD36, hormone-sensitive lipase, and Janus kinase 2, which subsequently transmit multiple inflammation signals. ${ }^{33}$ Our immunohistochemical analyses suggested that FABP4 was overexpressed in $\alpha$-SMA-positive HSCs activated in the stroma of human and murine HCC tissues associated with metabolic diseases (Figure 3).

Intratumoral-activated HSCs promote HCC cell proliferation and migration directly or indirectly through the production of growth factors and cytokines. ${ }^{34}$ The overexpression of FABP4 in human-activated HSC LX2 cells stimulated NF- $\kappa \mathrm{B}$ signaling pathway and then further increased the expression levels of proinflammatory cytokines (Figure 4). These were close to the previous findings in macrophages that FABP4 restricts the availability of fatty acids that inhibit the NF-kB pathway, resulting in the blockade of inflammatory response. ${ }^{33}$ Treatment with NF- $\kappa \mathrm{B}$ inhibitor SN50 attenuated the elevation of cytokines in the LX2-FABP4 cells (Figure 5), suggesting that FABP4 contributes to 
inflammatory signals through NF- $\kappa \mathrm{B}$ signaling in HSCs. The cytokines up-regulated through the FABP4-NF- $\mathrm{KB}$ axis in HSCs included CXCL3, CXCL5, CXCL8, IL-1A, IL-6, and IL-33, which are known to play important roles in activation of neutrophils, macrophages, regulatory $\mathrm{T}$ cells, and endothelial cells that compose the tumor microenvironment. ${ }^{35}$ It is possible that activated HSCs with FABP4 expression might influence the growth and evolution of HCC-MRFs to alter the tumor microenvironment.

Expression of FABP4 is stimulated by multiple factors, including fatty acids, insulin, inflammation, ${ }^{33}$ hypoxia, ${ }^{36}$ altered gut microbiota, ${ }^{37}$ and DNA damage. ${ }^{38}$ Several experimental data repeatedly indicated that free fatty acids stimulated FABP4 production and secretion in HCC cells. ${ }^{33}$ Yoshimoto et al ${ }^{39}$ reported that obesity induced the microbiota alterations, which in turn caused DNA damage in HSCs of the liver, and resulted in secretion of various inflammatory cytokines to facilitate HCC development. Of interest, we observed the same set of cytokines upregulated in the LX2-FABP4 cells. ${ }^{40}$ Further studies of control of FABP4 by gut microbiota alteration and DNA damage response with metabolic syndrome is required to clarify the molecular mechanisms of FABP4 expression in HSCs.

Several studies have addressed oncogenic properties of FABP4 in progression of malignancies. FABP4 is directly implicated in tumor growth and metastasis in ovarian cancers. ${ }^{24}$ Moreover, vascular endothelial cells express FABP4 through NOTCH signaling pathway in ovarian cancer tissues, and therapeutic siRNA-based knockdown of FABP4 markedly impairs tumor angiogenesis, growth, and metastasis in the mouse models. ${ }^{41}$ To date, several synthetic FABP4 inhibitors have emerged as potential treatment approaches for metabolic disorders. ${ }^{42}$ Because overexpression of FABP4 in intratumoral HSCs was possibly characteristic of HCC patients with MRFs, a therapeutic strategy to target FABP may also be effective for treatment of this disease.

Accumulating evidence suggests that FABP4 acts as a critical regulator of both metabolic and inflammatory pathways and that the up-regulation of FABP4 is strongly related to obesity, type 2 diabetes, arteriosclerosis, and steatohepatitis. $^{21,33}$ Several studies have indicated that accumulation of MRFs is closely associated with the severity of atherosclerosis and coronary artery diseases. ${ }^{43,44}$ Similarly, the coexistence of obesity and diabetes raises the risk of cancer and cancer-related death, implying that treatment of each disease could reduce cancer risk. ${ }^{45}$ In our clinicopathologic studies, the expression of FABP4 was tightly linked to the increased number of MRFs in the patients (Figure 7B). Decreasing the MRFs in a stepwise manner may attenuate FABP4 expression and may sequentially limit HCC risk in each case. ${ }^{46}$ Further studies are required, such as identification of FABP4 expression in HSCs as a surrogate marker for immunotherapy, and endogenous and exogenous regulation of FABP4 as a therapeutic target in this subtype of HCC.

\section{Acknowledgments}

We thank Profs. Tomokazu Matsuura (The Jikei University School of Medicine, Tokyo, Japan) and Masahisa Jinushi (Keio University, Tokyo, Japan), respectively, for TWNT4 and THP-1 cell lines; Dr. Hiroyuki Miyoshi (RIKEN BioResource Center, Ibaraki, Japan) for CSII-EF-MCS plasmid; Dr. Irvin Chen (University of California, Los Angeles, Los Angeles, CA) for pCMVDR8.2 and pHCMV-VSV-G lentiviral vectors; and Hiromi Nagasaki for technical assistance.

\section{Supplemental Data}

Supplemental material for this article can be found at https://doi.org/10.1016/j.ajpath.2018.01.012.

\section{References}

1. Ferlay J, Soerjomataram I, Dikshit R, Eser S, Mathers C, Rebelo M, Parkin DM, Forman D, Bray F: Cancer incidence and mortality worldwide: sources, methods and major patterns in GLOBOCAN 2012. Int J Cancer 2015, 136:E359-E386

2. Bruix J, Gores GJ, Mazzaferro V: Hepatocellular carcinoma: clinical frontiers and perspectives. Gut 2014, 63:844-855

3. Welzel TM, Graubard BI, Zeuzem S, El-Serag HB, Davila JA, McGlynn KA: Metabolic syndrome increases the risk of primary liver cancer in the United States: a study in the SEER-Medicare database. Hepatology 2011, 54:463-471

4. El-Serag HB, Kanwal F: Epidemiology of hepatocellular carcinoma in the United States: where are we? Where do we go? Hepatology 2014, 60:1767-1775

5. Akahoshi K, Tanaka S, Mogushi K, Shimada S, Matsumura S, Akiyama Y, Aihara A, Mitsunori Y, Ban D, Ochiai T, Kudo A, Arii S, Tanabe M: Expression of connective tissue growth factor in the livers of non-viral hepatocellular carcinoma patients with metabolic risk factors. J Gastroenterol 2016, 51:910-922

6. Calle EE, Rodriguez C, Walker-Thurmond K, Thun MJ: Overweight, obesity, and mortality from cancer in a prospectively studied cohort of U.S. adults. N Engl J Med 2003, 348:1625-1638

7. El-Serag HB, Hampel H, Javadi F: The association between diabetes and hepatocellular carcinoma: a systematic review of epidemiologic evidence. Clin Gastroenterol Hepatol 2006, 4:369-380

8. Maher JJ: Modeling fatty liver disease in animals: is there an optimal approach, and is the effort worthwhile? Hepatology 2016, 64: $1398-1400$

9. Kirsch R, Clarkson V, Shephard EG, Marais DA, Jaffer MA, Woodburne VE, Kirsch RE, Hall Pde L: Rodent nutritional model of non-alcoholic steatohepatitis: species, strain and sex difference studies. J Gastroenterol Hepatol 2003, 18:1272-1282

10. Hill-Baskin AE, Markiewski MM, Buchner DA, Shao H, DeSantis D, Hsiao G, Subramaniam S, Berger NA, Croniger C, Lambris JD, Nadeau JH: Diet-induced hepatocellular carcinoma in genetically predisposed mice. Hum Mol Genet 2009, 18:2975-2988

11. Fujii M, Shibazaki Y, Wakamatsu K, Honda Y, Kawauchi Y, Suzuki K, Arumugam S, Watanabe K, Ichida T, Asakura H, Yoneyama H: A murine model for non-alcoholic steatohepatitis showing evidence of association between diabetes and hepatocellular carcinoma. Med Mol Morphol 2013, 46:141-152

12. Horie Y, Suzuki A, Kataoka E, Sasaki T, Hamada K, Sasaki J, Mizuno K, Hasegawa G, Kishimoto H, lizuka M, Naito M, Enomoto K, Watanabe S, Mak TW, Nakano T: Hepatocyte-specific 
Pten deficiency results in steatohepatitis and hepatocellular carcinomas. J Clin Invest 2004, 113:1774-1783

13. Vaisse C, Clement K, Durand E, Hercberg S, Guy-Grand B, Froguel P: Melanocortin-4 receptor mutations are a frequent and heterogeneous cause of morbid obesity. J Clin Invest 2000, 106:253-262

14. Itoh M, Suganami T, Nakagawa N, Tanaka M, Yamamoto $Y$, Kamei Y, Terai S, Sakaida I, Ogawa Y: Melanocortin 4 receptordeficient mice as a novel mouse model of nonalcoholic steatohepatitis. Am J Pathol 2011, 179:2454-2463

15. Rosenthal N, Brown S: The mouse ascending: perspectives for humandisease models. Nat Cell Biol 2007, 9:993-999

16. Teufel A, Itzel T, Erhart W, Brosch M, Wang XY, Kim YO, von Schönfels W, Herrmann A, Brückner S, Stickel F, Dufour JF, Chavakis T, Hellerbrand C, Spang R, Maass T, Becker T, Schreiber S, Schafmayer C, Schuppan D, Hampe J: Comparison of gene expression patterns between mouse models of nonalcoholic fatty liver disease and liver tissues from patients. Gastroenterology 2016, 151:513-525

17. Hara M, Inoue I, Yamazaki Y, Kirita A, Matsuura T, Friedman SL, Rifkin DB, Kojima S: L ${ }^{59}$ TGF-beta LAP degradation products serve as a promising blood biomarker for liver fibrogenesis in mice. Fibrogenesis Tissue Repair 2015, 8:17

18. Oba A, Shimada S, Akiyama Y, Nishikawaji T, Mogushi K, Ito H, Matsumura S, Aihara A, Mitsunori Y, Ban D, Ochiai T, Kudo A, Asahara H, Kaida A, Miura M, Tanabe M, Tanaka S: ARID2 modulates DNA damage response in human hepatocellular carcinoma cells. J Hepatol 2017, 66:942-951

19. Cataltepe O, Arikan MC, Ghelfi E, Karaaslan C, Ozsurekci Y, Dresser K, Li Y, Smith TW, Cataltepe S: Fatty acid binding protein 4 is expressed in distinct endothelial and non-endothelial cell populations in glioblastoma. Neuropathol Appl Neurobiol 2012, 38:400-410

20. Starley BQ, Calcagno CJ, Harrison SA: Nonalcoholic fatty liver disease and hepatocellular carcinoma: a weighty connection. Hepatology 2010, 51:1820-1832

21. Furuhashi M, Tuncman G, Görgün CZ, Makowski L, Atsumi G, Vaillancourt E, Kono K, Babaev VR, Fazio S, Linton MF, Sulsky R, Robl JA, Parker RA, Hotamisligil GS: Treatment of diabetes and atherosclerosis by inhibiting fatty-acid-binding protein aP2. Nature 2007, 447:959-965

22. Roca-Rivada A, Bravo SB, Pérez-Sotelo D, Alonso J, Castro AI, Baamonde I, Baltar J, Casanueva FF, Pardo M: CILAIR-based secretome analysis of obese visceral and subcutaneous adipose tissues reveals distinctive ECM remodeling and inflammation mediators. Sci Rep 2015, 5:12214

23. Xie L, Wang PX, Zhang P, Zhang XJ, Zhao GN, Wang A, Guo J, Zhu X, Zhang Q, Li H: DKK3 expression in hepatocytes defines susceptibility to liver steatosis and obesity. J Hepatol 2016, 65: $113-124$

24. Nieman KM, Kenny HA, Penicka CV, Ladanyi A, Buell-Gutbrod R, Zillhardt MR, Romero IL, Carey MS, Mills GB, Hotamisligil GS, Yamada SD, Peter ME, Gwin K, Lengyel E: Adipocytes promote ovarian cancer metastasis and provide energy for rapid tumor growth. Nat Med 2011, 17:1498-1503

25. Naschberger E, Liebl A, Schellerer VS, Schütz M, Britzen-Laurent N, Kölbel P, Schaal U, Haep L, Regensburger D, Wittmann T, KleinHitpass L, Rau TT, Dietel B, Méniel VS, Clarke AR, Merkel S, Croner RS, Hohenberger W, Stürzl M: Matricellular protein SPARCL1 regulates tumor microenvironment-dependent endothelial cell heterogeneity in colorectal carcinoma. J Clin Invest 2016, 126:4187-4204

26. Pei $\mathrm{Y}$, Kano J, Iijima $\mathrm{T}$, Morishita $\mathrm{Y}$, Inadome $\mathrm{Y}$, Noguchi M: Overexpression of Dickkopf 3 in hepatoblastomas and hepatocellular carcinomas. Virchows Arch 2009, 454:639-646

27. Kordes C, Sawitza I, Götze S, Häussinger D: Hepatic stellate cells support hematopoiesis and are liver-resident mesenchymal stem cells. Cell Physiol Biochem 2013, 31:290-304

28. Graupera I, Coll M, Pose E, Elia C, Piano S, Solà E, Blaya D, Huelin P, Solé C, Moreira R, de Prada G, Fabrellas N, Juanola A,
Morales-Ruiz M, Sancho-Bru P, Villanueva C, Ginès P: Adipocyte fatty-acid binding protein is overexpressed in cirrhosis and correlates with clinical outcomes. Sci Rep 2017, 7:1829

29. Graeber TG, Sawyers CL: Cross-species comparisons of cancer signaling. Nat Genet 2005, 37:7-8

30. Stahl S, Ittrich C, Marx-Stoelting P, Köhle C, Altug-Teber O, Riess O, Bonin M, Jobst J, Kaiser S, Buchmann A, Schwarz M: Genotypephenotype relationships in hepatocellular tumors from mice and man. Hepatology 2005, 42:353-361

31. Lee JS, Chu IS, Mikaelyan A, Calvisi DF, Heo J, Reddy JK, Thorgeirsson SS: Application of comparative functional genomics to identify best-fit mouse models to study human cancer. Nat Genet 2004, 36:1306-1311

32. Hotamisligil GS, Erbay E: Nutrient sensing and inflammation in metabolic diseases. Nat Rev Immunol 2008, 8:923-934

33. Hotamisligil GS, Bernlohr DA: Metabolic functions of FABPsmechanisms and therapeutic implications. Nat Rev Endocrinol 2015, 11:592-605

34. Coulouarn C, Clément B: Stellate cells and the development of liver cancer: therapeutic potential of targeting the stroma. J Hepatol 2014, 60:1306-1309

35. Lazennec G, Richmond A: Chemokines and chemokine receptors: new insights into cancer-related inflammation. Trends Mol Med 2010, 16 : $133-144$

36. Hu B, Guo Y, Garbacz WG, Jiang M, Xu M, Huang H, Tsung A, Billiar TR, Ramakrishnan SK, Shah YM, Lam KS, Huang M, Xie W: Fatty acid binding protein-4 (FABP4) is a hypoxia inducible gene that sensitizes mice to liver ischemia/reperfusion injury. J Hepatol 2015, 63:855-862

37. Su X, Yan H, Huang Y, Yun H, Zeng B, Wang E, Liu Y, Zhang Y, Liu F, Che Y, Zhang Z, Yang R: Expression of FABP4, adipsin and adiponectin in Paneth cells is modulated by gut Lactobacillus. Sci Rep 2015, 5:18588

38. Kostyuk S, Smirnova T, Kameneva L, Porokhovnik L, Speranskij A, Ershova E, Stukalov S, Izevskaya V, Veiko N: GC-rich extracellular DNA induces oxidative stress, double-strand DNA breaks, and DNA damage response in human adipose-derived mesenchymal stem cells. Oxid Med Cell Longev 2015, 2015:782123

39. Yoshimoto S, Loo TM, Atarashi K, Kanda H, Sato S, Oyadomari S, Iwakura Y, Oshima K, Morita H, Hattori M, Honda K, Ishikawa Y, Hara E, Ohtani N: Obesity-induced gut microbial metabolite promotes liver cancer through senescence secretome. Nature 2013, 499:97-101

40. Rodier F, Coppé JP, Patil CK, Hoeijmakers WA, Muñoz DP, Raza SR, Freund A, Campeau E, Davalos AR, Campisi J: Persistent DNA damage signalling triggers senescence-associated inflammatory cytokine secretion. Nat Cell Biol 2009, 11:973-979

41. Harjes U, Bridges E, Gharpure KM, Roxanis I, Sheldon H, Miranda F, Mangala LS, Pradeep S, Lopez-Berestein G, Ahmed A, Fielding B, Sood AK, Harris AL: Antiangiogenic and tumour inhibitory effects of downregulating tumour endothelial FABP4. Oncogene 2017, 36: 912-921

42. Crunkhorn S: Metabolic disease: targeting aP2 reverses diabetes. Nat Rev Drug Discov 2016, 15:86

43. Berenson GS, Srinivasan SR, Bao W, Newman WP III, Tracy RE, Wattigney WA: Association between multiple cardiovascular risk factors and atherosclerosis in children and young adults. The Bogalusa Heart Study. N Engl J Med 1998, 338:1650-1656

44. Solymoss BC, Bourassa MG, Campeau L, Sniderman A, Marcil M, Lespérance J, Lévesque S, Varga S: Effect of increasing metabolic syndrome score on atherosclerotic risk profile and coronary artery disease angiographic severity. Am J Cardiol 2004, 93:159-164

45. Gallagher EJ, LeRoith D: Obesity and diabetes: the increased risk of cancer and cancer-related mortality. Physiol Rev 2015, 95:727-748

46. Daniels SR, Pratt CA, Hayman LL: Reduction of risk for cardiovascular disease in children and adolescents. Circulation 2011, 124: $1673-1686$ 